\title{
Safety profile of trifluridine/tipiracil monotherapy in clinical practice: results of the German compassionate-use program for patients with metastatic colorectal cancer
}

Stefan Kasper ${ }^{1 *}$ (D) Jens Kisro ${ }^{2}$, Martin Fuchs ${ }^{3}$, Christian Müller ${ }^{4}$, Armin Schulz-Abelius ${ }^{5}$, Meinolf Karthaus ${ }^{6}$, Mohammad-Reza Rafiyan ${ }^{7}$ and Alexander Stein $^{8}$

\begin{abstract}
Background: Trifluridine/tipiracil (TAS-102, Lonsurf ${ }^{\oplus}$ ), a novel oral anti-tumor agent combining an anti-neoplastic thymidine-based nucleoside analogue (trifluridine, FTD) with a thymidine phosphorylase inhibitor (tipiracil hydrochloride, TPI) presents a new treatment option for metastatic colorectal cancer (mCRC) patients refractory or intolerant to standard therapies. FTD/TPI was approved in the European Union (EU) in April 2016 and launched on the German market in August 15, 2016.

Methods: We investigated the characteristics of patients (pts) with mCRC treated with FTD/TPI at 118 centers in Germany from January 12 to August 14, 2016 and analyzed the safety in a clinical real-world setting.

Results: In Germany, a total of 226 mCRC patients were included into a compassionate-use-program (CUP) and received FTD/TPI. For $45.5 \%$ of patients ( $n=101), 253$ adverse events (AE) were documented, most of them drug-related $(n=135)$. From January 12 (2016) to March 2 (2017), 124 serious adverse events (SAE) were reported (74 drug related). The most common serious adverse drug reactions (SADR) were leukopenia (12 events), neutropenia (8 events), anemia (7 events), diarrhea and nausea (5 events each) (observation period January 122016 to October 7 2016). In total, 122 patients (54\%) discontinued FTD/TPI treatment, mostly due to progression $(n=75)$ followed by AEs $(n=21)$, deaths $(n=16)$, and nonspecified reasons $(n=16)$. Interestingly, 12 patients with ECOG PS $\geq 2$ achieved up to 3 cycles of FTD/TPI and in this patient population only 3 treatment discontinuations due to AEs were documented and the safety profile was comparable to the entire population.
\end{abstract}

Conclusion: The patient characteristics as well as the safety profile of FTD/TPI documented in the German CUP were consistent with those reported in the pivotal trial RECOURSE without unexpected safety signals.

Keywords: Metastatic colorectal carcinoma, Trifluridine/tipiracil, TAS-102, Real world oncology

\footnotetext{
* Correspondence: stefan.kasper@uk-essen.de

${ }^{1}$ West German Cancer Center, Department of Medical Oncology, University

Hospital Essen, Essen, Hufelandstrasse 55, 45147 Essen, Germany

Full list of author information is available at the end of the article
}

(c) The Author(s). 2018 Open Access This article is distributed under the terms of the Creative Commons Attribution 4.0 International License (http://creativecommons.org/licenses/by/4.0/), which permits unrestricted use, distribution, and reproduction in any medium, provided you give appropriate credit to the original author(s) and the source, provide a link to the Creative Commons license, and indicate if changes were made. The Creative Commons Public Domain Dedication waiver (http://creativecommons.org/publicdomain/zero/1.0/) applies to the data made available in this article, unless otherwise stated. 


\section{Background}

Colorectal cancer (CRC) is the third most common cancer in Germany [1]. During the last two decades, new combination chemotherapies (e.g with oxaliplatin, irinotecan, and flouropyrimidines) and the development of therapeutic monoclonal antibodies (e.g bevacizumab, cetuximab, panitumumab and ramucirumab) and other targeted agents (e.g. aflicercept, regorafenib) have notably prolonged the median survival time of pts. with metastatic CRC (mCRC). In recent clinical trials, the median overall survival (OS) from first-line therapy in metastatic disease has reached approximately 30 months [2-8]. Nevertheless, the prognosis of patients, which are refractory or intolerant to all approved drugs is poor and there is still an unmet medical need for these patients [9-13], especially for those who are in a good performance status and eligible for further therapies.

FTD/TPI is an oral antimetabolite and has been shown to be effective in the treatment of patients refractory or intolerant to approved drugs for mCRC [14]. The drug combines trifluridine, a thymidine-based nucleoside analogue, and tipiracil, which improves the bioavailability of trifluridine by inhibiting the enzyme thymidine phosphorylase, which is involved in its catabolism [15]. In the randomized global phase 3 trial RECOURSE FTD/TPI prolonged OS and progression free survival (PFS) compared to placebo with a favorable safety profile [14]. In the RECOURSE trial, 800 pts. with mCRC refractory or intolerant to fluoropyrimidine, irinotecan, oxaliplation, bevacizumab and to epidermal growth factor (EGFR) antibodies (in pts. with KRAS wild-type tumors) were randomly assigned in a 2:1 ratio to either FTD/TPI $\left(35 \mathrm{mg} / \mathrm{m}^{2}\right.$ per dose twice daily on days 1 to 5 and 8 to 12 , every four weeks) or placebo. In addition in both study arms patients received best supportive care (BSC). FTD/TPI, significantly prolonged median OS compared to placebo (7.1 vs. 5.3 months; hazard ratio (HR) $0.68 ; p<0.0001$ ). In addition FTD/TPI significantly prolonged median PFS; 2.0 vs. 1.7 Months; HR 0.48; $p<$ $0.0001)$, improved disease control rate ((DCR; $44.0 \%$ vs. $16.3 \% ; \mathrm{p}<0.0001)$ and prolonged median time to deterioration of ECOG performance status compared to placebo. FTD/TPI was well tolerated in the RECOURSE trial. The most overall common adverse events (AE) were leukopenia, neutropenia, anemia and thrombocytopenia and the most common $\mathrm{AE} \geq$ grade 3 was neutropenia (38\% of patients treated with FTD/TPI).

However, data from clinical trials does not always reflect clinical experience in a real-life setting. In RECOURSE, for example, patients with ECOG performance status $\geq 2$ were excluded and the rate of patient who had received regorafenib prior to FTD/TPI was only $18 \%$. This is explained by the lack of approval of regorafenib at the time point of initiation of the
RECOURSE trial. Thus, little information is available regarding the safety profile of FTD/TPI for patients with poor performance status or patients that had been pretreated with regorafenib.

To collect more information about the usage and tolerability of FTD/TPI in clinical practice, we prospectively investigated the characteristics of patients with mCRC refractory or intolerant to standard chemotherapies treated with FTD/TPI monotherapy within a compassionate use program (CUP), which was conducted from January 12 to August 14, 2016 in designated CRC centers in Germany and compared the rate and severity of AE to the data from the phase III trial RECOURSE. CUPs provide treatment options for patients with unmet medical needs and offer the opportunity to obtain early data on efficacy, safety and use of a new drug in a real-world setting. In our analysis, we differentiated between patients who had received regorafenib prior to treatment with FTD/TPI and those who had not.

\section{Methods \\ Patients and data analysis}

This was a prospective study of pretreated patients with mCRC who had received FTD/TPI at 118 designated CRC centers of the German Cancer Society (DKG) with high expertise in treating patients with advanced CRC from 12th January to 14th August 2016. Sites were selected based on the availability of a certification for interdisciplinary management of colorectal cancer by the German Cancer Society (Darmkrebszentrum). All data were collected within the German CUP for FTD/TPI prior to the regular market access in September 2016. All patients must have had a histologically confirmed adenocarcinoma of the colon or rectum and must have been previously treated for metastatic disease with, or have not been candidates for, available therapies including fluoropyrimidines, oxaliplatin, irinotecan, anti-VEGF agents and anti-EGFR agents in case of $R A S$ wild-type status. After written informed consent, patients could be included into the CUP if they were $\geq 18$ years of age and had adequate organ function and appropriate neutrophil $\left(\geq 1.5 \times 10^{9} / 1\right)$ and platelet $\left(\geq 75 \times 10^{9} / 1\right)$ count. The baseline characteristics collected for each patient included age, sex, ECOG performance status, vital signs (height, weight, body mass index, body surface area and - calculated on the basis of these values - daily dose of FTD/ TPI), colorectal surgery (yes/no), KRAS or all RAS mutational status, time since diagnosis, adjuvant chemotherapy (yes/no), and prior use of regorafenib (yes/no). No data concerning $B R A F$ mutational status or mismatch repair deficiency (dMMR) was collected. The body surface area was calculated using the following DuBois formula (all BSA calculations were rounded to 2 decimal places): BSA $\left(\mathrm{m}^{2}\right)=\left([\text { Body Weight }(\mathrm{kg})]^{0.425} \times\right.$ [Height 
$\left.(\mathrm{cm})]^{0.725}\right) \times 0.007184$ [16]. AE were documented and graded by the investigators using the Common Terminology Criteria for adverse events (CTCAE) in its current version. All data were collected pseudonymously in an electronic data base and were statistically analyzed using the Statistical Analysis System (SAS) version 9.4. software AEs were classified based on the ICH-MeDRA medical terminology.

\section{Results}

\section{Patient characteristics}

A total of 254 patients (58.4\% male and $41.6 \%$ female) were enrolled into the CUP with FTP/TPI in Germany. Six patients were not eligible for the treatment with FTD/TPI and 22 patients were eligible but did not start treatment. The data of the remaining 226 patients (100\%) was included in this analysis. The mean age of patients was 63.15 years with $36.7 \%$ of patients being younger than 60 years, $33.2 \%$ between 60 and 70 years and $30.1 \%$ older than 70 years, respectively. Of the 226 patients, 28, 62.2, and 9.8\% had an ECOG performance status of 0,1 , and $\geq 2$, respectively. Median time from diagnosis of metastatic disease until enrolment into the CUP was 36.4 months (5-144 months) with $75.7 \%$ of patients having been diagnosed $\geq 24$ months. KRAS wild-type tumors were documented for $46.4 \%$ of patients, and KRAS mutant tumors for $53.6 \%$ in our patient population. Comorbidities were documented for $54.4 \%$ of patients including hypertension (17.7\%), thromboembolic events (15.05\%), diabetes mellitus (4.87\%), hypothyroidism (4.87\%), coronary artery disease (3.1\%), polyneuropathy (2.65\%), type 2 diabetes mellitus $(2.21 \%)$, atrial fibrillation (1.77\%), benign prostatic hyperplasia (1.77\%) and breast cancer (1.77\%). Most patients $(88.9 \%)$ had have colorectal surgery and $36.9 \%$ of patients had received an adjuvant chemotherapy. The mean body surface area of the patients was $1.87 \mathrm{~m}^{2}$; consequently patients received a mean daily dose of FTD/ TPI of $130 \mathrm{mg}$. In Table 1, patient baseline characteristics of the German CUP-population are summarized.

\section{Pretreatment}

Prior enrollment into the CUP and treatment with FTD/ TPI, $98.67 \%$ of patients received an irinotecan-based regime, $88.05 \%$ received an oxaliplatin-based regimen. $97.35 \%$ received infusional 5 -fluorouracil and $25.66 \%$ received capecitabine. The monoclonal VEGF antibody bevacizumab was applied to $85.4 \%$ of patients in previous treatment lines, 33.63 and $26.11 \%$ had received the monoclonal EGFR antibodies cetuximab and panitumumab, respectively (Table 2). Pretreatment with regorafenib was documented for $33.63 \%$, with aflibercept for $27.88 \%$, and with ramucirumab for $1.77 \%$ of patients.
Table 1 Patient characteristics of the German compassionateuse-program (CUP) for FTD/TPIP

\begin{tabular}{|c|c|c|}
\hline Characteristics & $\begin{array}{l}\text { Number of Patients } \\
\text { in the German } \\
\text { FTD/TPI CUP }\end{array}$ & $\begin{array}{l}\% \text { of Patients in the } \\
\text { German FTD/TPI CUP }\end{array}$ \\
\hline $\begin{array}{l}\text { Patients (application by } \\
\text { medical practitioner) }\end{array}$ & 254 & - \\
\hline Non-eligible patients & 6 & - \\
\hline $\begin{array}{l}\text { Eligible patients without } \\
\text { treatment onset }\end{array}$ & 22 & - \\
\hline $\begin{array}{l}\text { Eligible patients with Lonsurf } \\
\text { treatment onset }\end{array}$ & 226 & $100 \%$ \\
\hline Mean age (years) & 63.15 & \\
\hline$<60$ years & 83 & $36.7 \%$ \\
\hline$<70$ years & 75 & $33.2 \%$ \\
\hline$>70$ years & 68 & $30.1 \%$ \\
\hline \multicolumn{3}{|l|}{ Sex } \\
\hline Male & 132 & $58.4 \%$ \\
\hline Female & 94 & $41.6 \%$ \\
\hline \multicolumn{3}{|l|}{ ECOG performance status ${ }^{a}$} \\
\hline 0 & 63 & $28 \%$ \\
\hline 1 & 140 & $62.2 \%$ \\
\hline$\geq 2$ & 22 & $9.8 \%$ \\
\hline \multicolumn{3}{|l|}{ Vital signs } \\
\hline Mean height $(\mathrm{cm})$ & 172.1 & - \\
\hline Mean weight (kg) & 74.2 & - \\
\hline $\begin{array}{l}\text { Mean body mass } \\
\text { index }\left(\mathrm{kg} / \mathrm{m}^{2}\right) \text { (range) }\end{array}$ & $25(14.7-43.6)$ & - \\
\hline $\begin{array}{l}\text { Mean body surface } \\
\text { area }\left(\mathrm{m}^{2}\right)^{c}\end{array}$ & 1.87 & \\
\hline $\begin{array}{l}\text { Mean daily dose of } \\
\text { FTD/TPI }\end{array}$ & $130 \mathrm{mg}$ & \\
\hline \multicolumn{3}{|l|}{ Colorectal surgery } \\
\hline Yes & 201 & $88.9 \%$ \\
\hline No & 25 & $11.1 \%$ \\
\hline \multicolumn{3}{|l|}{ KRAS status ${ }^{a}$} \\
\hline Wild type & 103 & $46.4 \%$ \\
\hline Mutant & 119 & $53.6 \%$ \\
\hline \multicolumn{3}{|c|}{ Time from diagnosis of metastatic disease } \\
\hline$<24$ months & 55 & $24.3 \%$ \\
\hline$\geq 24$ months & 171 & $75.7 \%$ \\
\hline \multicolumn{3}{|l|}{ Prior use of Regorafenib } \\
\hline Yes & 76 & $33.6 \%$ \\
\hline No & 150 & $66.4 \%$ \\
\hline \multicolumn{3}{|l|}{ Adjuvant chemotherapy ${ }^{d}$} \\
\hline Yes & 82 & $36.9 \%$ \\
\hline No & 140 & $63.1 \%$ \\
\hline
\end{tabular}

${ }^{\mathrm{a}} 4 \mathrm{mCRC}$ patients without KRAS status assessment

${ }^{b}$ This information is missing for 1 patient

'The BSA was calculated using the following DuBois formula (all BSA calculations were rounded to 2 decimal places): BSA $\left(\mathrm{m}^{2}\right)=($ [Body Weight $\left.(\mathrm{kg})]^{0.425} \times[\text { Height }(\mathrm{cm})]^{0.725}\right) \times 0.007184$

dTe information for $4 \mathrm{mCRC}$ patients is not available Abbreviation: not available, n.a 
Table 2 Prior regimes of the $\mathrm{mCRC}$ patients in the German compassionate-use-program of FTD/TPI

\begin{tabular}{lll}
\hline $\begin{array}{l}\text { Lead Substance of } \\
\begin{array}{l}\text { Combination } \\
\text { Treatment (if applicable) }\end{array}\end{array}$ & $\begin{array}{l}\text { Number of Patients in } \\
\text { the German FTD/TPI }\end{array}$ & $\begin{array}{l}\text { \% of Patients in the } \\
\text { German FTD/TPI CUP }\end{array}$ \\
\hline Fluorouracil & 220 & $97.35 \%$ \\
Irinotecan & 223 & $98.67 \%$ \\
Oxaliplatin & 199 & $88.05 \%$ \\
Bevacizumab & 193 & $85.4 \%$ \\
Cetuximab & 76 & $33.63 \%$ \\
Panitumumab & 59 & $26.11 \%$ \\
Regorafenib & 76 & $33.63 \%$ \\
Aflibercept & 63 & $27.88 \%$ \\
Ramucirumab & 4 & $1.77 \%$ \\
Mitomycin & 17 & $7.52 \%$ \\
\hline
\end{tabular}

a some patients received both EGFR antibodies

One $\mathrm{mCRC}$ patient each received gemcitabine, carboplatin, pembrolizumab, nintedanib or niclosamide

Abbreviations: EGFR, epithelial growth factor receptor; monoclonal antibodies, mabs; not available, n.a

Mitomycin was applied to $7.52 \%$ of patients before enrollment into the CUP.

\section{Treatment}

On average, the patients received 2.5 cycles of FTD/TPI within the CUP with a mean dose of $130 \mathrm{mg}$. FTP/TPI supply within the CUP was stopped in September 2016 after the regular market access was granted. In this context it should be noted that $46 \%$ mCRC patients (46\%) continued treatment after the regular market access of FTD/TPI. Unfortunately, due to regulatory affairs the follow-up data of these patients were not available. In line, it was not possible to determine the average number of cycles of the whole CUP patient population.

Discontinuation of treatment was documented in 122 patients (54\%), in most cases due to progression (61.5\%), followed by AEs (17.2\%), deaths (13.1\%), and non-specified reasons $(8.2 \%)$. The AEs which lead to discontinuation of FTP/TPI included: general physical health deterioration ( 4 events), fatigue (3 events), dyspnea (2 events), pyrexia (2 events), anemia, decreased appetite, renal failure, abdominal pain, diarrhea, nausea, leukopenia, decreased weight, constipation, device-related infection and/or hyperbilirubinemia. Interestingly, the time since the last disease progression after the previous treatment line till enrollment into the CUP did not correlate with the likelihood of FTD/TPI treatment discontinuation (Table 3). This suggests that patients with rapid as well as slowly progressive disease benefit from FTP/TPI treatment.

\section{Safety}

Safety was evaluated for all 226 patients enrolled into the CUP. For 101 patients (45\%) 253 AEs were documented,
Table 3 Last disease progression in the previous treatment line in relation to the discontinuation of treatment with FTD/TPI

\begin{tabular}{|c|c|c|c|c|c|}
\hline \multirow{3}{*}{$\begin{array}{l}\text { Last Disease } \\
\text { Progression }^{a}\end{array}$} & \multicolumn{4}{|c|}{ Discontinuation of FTD/TPI Treatment } & \multirow{3}{*}{$\begin{array}{l}\text { mCRC Patient } \\
\text { Number } \\
\text { (In Total) } \\
\text { n }\end{array}$} \\
\hline & \multicolumn{2}{|c|}{ Yes } & \multicolumn{2}{|c|}{ No } & \\
\hline & $\bar{n}$ & $\%$ & $\mathrm{n}$ & $\%$ & \\
\hline$\leq 7$ Days & 38 & 58.72 & 29 & 43.28 & 67 \\
\hline $1-<2$ Weeks & 25 & 59.52 & 17 & 40.48 & 42 \\
\hline $2-<3$ Weeks & 12 & 52.17 & 11 & 47.83 & 23 \\
\hline $3-<4$ Weeks & 12 & 50.0 & 12 & 50.00 & 24 \\
\hline \multirow[t]{2}{*}{$>4$ Weeks } & 30 & 47.62 & 33 & 52.38 & 63 \\
\hline & & & & & 219 \\
\hline
\end{tabular}

${ }^{\mathrm{a}}$ Appropriate data from $7 \mathrm{mCRC}$ patients were not available

138 of them reported as drug-related by the investigators (Table 4). The frequency of AEs was comparable to those of the RECOURSE trial, where 524 AEs were reported in 533 patients (Table 4). Most common AEs in the FTD/ TPI CUP population were leukopenia $(n=25)$, neutropenia $(n=19)$, anemia $(n=15)$, nausea $(n=15)$, diarrhea $(n=11)$, fatigue $(n=9)$, fever $(n=9=$, asthenia $(n=9)$ and vomiting $(n=7)$.

From 12th January 2016 to 2nd March 2017, 124 (55\%) SAEs were reported (74 of them drug related by investigator's judgment). The incidence of SAEs were slightly higher than in the RECOURSE trial, where 158 (30\%) SAEs were reported in 533 patients (Table 4). The most common Serious Adverse Drug Reactions (SADR) in the here reported patient population were leukopenia (13 events), neutropenia (9 events), anemia (7 events), diarrhea, fatigue and nausea (5 events each) during the observation period between 12th of January 2016 to 7th of October 2016. The observed non-hematological SADR were comparable to those reported in the RECOURSE trial (Table 4). However, the incidence of hematological SADRs and other laboratory abnormalities were significantly lower in the German CUP than in the RECOURSE trial.

Notably, 12 patients with ECOG PS $\geq 2$ received treatment with up to 3 cycles of FTD/TPI (4 patients 1 cycle, 6 patients 2 cycles, 2 patients 3 cycles). Among these patients, only 3 discontinuations were due to AEs (cough, fatigue, esophageal candidiasis), the others were due to progression $(n=4)$, death $(n=1)$, and non-specified reasons $(n=3)$. In $9(40 \%)$ out of the 22 patients with ECOG PS $\geq 2,24$ AEs were reported. The incidence, type and grade of the AEs in patients with ECOG PS $\geq 2$ did not differ from those reported in the entire population of the FTD/TPI CUP ( $p=$ 0.753, chi-square) (Table 5).

In total 76 patients (69 with ECOG PS 0/1 and 7 with ECOG PS $\geq 2$ ) were pretreated with regorafenib before 
Table 4 Adverse drug reaction profile for FTD/TPI in German Compassionate-Use-Program (CUP) and the RECOURSE trial

\begin{tabular}{|c|c|c|c|c|c|}
\hline \multirow[t]{2}{*}{ Adverse Events (AE) } & \multicolumn{3}{|c|}{$\begin{array}{l}\text { FTD/TPI } \\
(n=226 \text { patients) }\end{array}$} & \multicolumn{2}{|c|}{$\begin{array}{l}\text { RECOURSE - FTD/TPI } \\
(n=533 \text { patients }) \\
\end{array}$} \\
\hline & Total number & Related & Non-related & $\begin{array}{l}\text { Total number } \\
\text { Any Grade }\end{array}$ & Grade $\geq 3$ \\
\hline Any adverse event & 253 & 138 & 115 & 524 & 370 \\
\hline Any serious adverse event (SAE) - no. (\%) & $124^{c}(55)$ & $74^{d}(33)$ & $50^{e}(22)$ & $158(30)$ & n.a \\
\hline Most common $A E s^{b}$ - no. (\%) & $\begin{array}{l}\text { Total number } \\
\text { Any Grade }\end{array}$ & Serious & Non-serious & $\begin{array}{l}\text { Total number } \\
\text { Any Grade }\end{array}$ & Grade $\geq 3$ \\
\hline Nausea & $15(5.9)$ & $5(2.0)$ & $10(4.0)$ & $258(48)$ & $10(2)$ \\
\hline Diarrhea & $11(4.3)$ & $5(2.0)$ & $6(2.4)$ & $170(32)$ & $16(3)$ \\
\hline Fatigue & 9 (3.6) & $5(2.0)$ & $4(1.6)$ & $188(35)$ & $21(4)$ \\
\hline Influenza like illness/Pyrexia/Chills/Fever & 9 (3.6) & $3(1.2)$ & $6(2.4)$ & $99(19)$ & $7(1)$ \\
\hline General physical health deterioration/Asthenia & $8(3.2)$ & $5(2.0)$ & $3(1.2)$ & $97(18)$ & $18(3)$ \\
\hline Vomiting & $7(2.8)$ & $3(1.2)$ & $4(1.6)$ & $148(28)$ & $11(2)$ \\
\hline Abdominal pain & $7(2.8)$ & $4(1.6)$ & $3(1.2)$ & $113(21)$ & $13(2)$ \\
\hline Decreased appetite & $3(1.2)$ & $1(<1)$ & $2(<1)$ & n.a & n.a \\
\hline Urinary tract infection/Urosepis & $3(1.2)$ & $2(<1)$ & $1(<1)$ & n.a & n.a \\
\hline Constipation/subileus & $3(1.2)$ & $2(<1)$ & $1(<1)$ & n.a & n.a \\
\hline Condition aggravated & $3(1.2)$ & $3(1.2)$ & $0(0)$ & n.a & n.a \\
\hline Alopecia & $2(<1)$ & $0(0)$ & $2(<1)$ & n.a & n.a \\
\hline Musculoskeletal pain & $2(<1)$ & $1(<1)$ & $1(<1)$ & n.a & n.a \\
\hline \multicolumn{6}{|l|}{ Events associated with fluoropyrimidine treatment } \\
\hline Stomatitis/Oesophagitis & $2(<1)$ & $1(<1)$ & $1(<1)$ & $43(8)$ & $2(<1)$ \\
\hline Mucosal inflammation & $1(<1)$ & $0(0)$ & $1(<1)$ & n.a & n.a \\
\hline Oesophageal candidiasis & $1(<1)$ & $0(0)$ & $1(<1)$ & n.a & n.a \\
\hline Hand-foot syndrome & $0(0)$ & $0(0)$ & $0(0)$ & $12(2)$ & $0(0)$ \\
\hline Febrile neutropenia & $1(<1)$ & $1(<1)$ & $0(0)$ & $20(4)$ & $20(4)$ \\
\hline \multicolumn{6}{|l|}{ Laboratory abnormalities no. /no./total no. (\%) } \\
\hline Leukopenia & $25(9.9)$ & $13(5.1)$ & $12(4.7)$ & $407 / 528(67)$ & $113 / 528(21)$ \\
\hline Neutropenia & $19(7.5)$ & $9(3.6)$ & $10(4.0)$ & $353 / 528(67)$ & 200/528 (38) \\
\hline Anemia & $15(5.9)$ & $7(2.8)$ & $8(3.2)$ & $404 / 528(77)$ & $96 / 528(18)$ \\
\hline Thrombocytopenia & $7(2.8)$ & $4(1.6)$ & $3(1.2)$ & $223 / 528(42)$ & $27 / 28(5)$ \\
\hline Increase in total bilirubin & $4(1.6)$ & $3(1.2)$ & $1(<1)$ & 189/526 (36) & $45 / 526(9)$ \\
\hline Renal failure/Increase in creatinine level & $2(<1)$ & $1(<1)$ & $1(<1)$ & $71 / 527(13)$ & $5 / 527(<1)$ \\
\hline Increase in alanine aminotransferase level & $0(0)$ & $0(0)$ & $0(0)$ & $126 / 526(24)$ & $10 / 256(2)$ \\
\hline Increase in aspartate aminotransferase level & $1(<1)$ & $0(0)$ & $1(<1)$ & $155 / 524(30)$ & $23 / 524(4)$ \\
\hline Increase alkaline phosphatase level & $1(<1)$ & $0(0)$ & $1(<1)$ & 205/526 (39) & $42 / 526(8)$ \\
\hline
\end{tabular}

${ }^{2}$ Data based on Mayer et al., N. Engl. J. Med. 2015; 372: 1909-19

${ }^{\mathrm{b}}$ Not all single non-related AEs are listed

'SAEs documented for $50 \mathrm{mCRC}$ patients treated with FTD/TPI

dRelated SAEs documented for $20 \mathrm{mCRC}$ patients treated with FTD/TPI

${ }^{\mathrm{e}}$ Non-related SAEs documented for $30 \mathrm{mCRC}$ patients treated with FTD/TPI

Abbreviation: n.a., not available

the enrollment into the CUP. In general, there was no difference in the incidence and type of the AEs or SADRs between patients with and without regorafenib pretreatment (suppl. Table 3). Interestingly, the incidence of diarrhea was slightly higher in regorafenib-pretreated patients.

\section{Discussion}

In our prospective CUP conducted in heavily pretreated patients with mCRC in Germany, we found that patient characteristics as well as the safety profile of FTD/TPI were comparable with those reported in the pivotal RECOURSE trial [14]. Mean age of patients, gender 
Table 5 Adverse event profile for FTD/TPI in mCRC patients with ECOG $\geq 2$

\begin{tabular}{|c|c|c|c|c|}
\hline \multirow{2}{*}{$\frac{\text { Patient No. }^{a}}{1}$} & \multirow{2}{*}{$\frac{E C O G}{2}$} & \multirow{2}{*}{$\begin{array}{l}\text { MedDRA Preferred Term } \\
\text { Death }\end{array}$} & \multicolumn{2}{|c|}{ Adverse Drug Reaction } \\
\hline & & & Non-related & Serious \\
\hline & & Oedema peripheral & Non-related & Non-serious \\
\hline & & Skin ulcer & Non-related & Non-serious \\
\hline & & General physical health deterioration & Non-related & Non-serious \\
\hline \multirow[t]{3}{*}{$6^{\mathrm{b}}$} & 2 & Cough & Non-related & Non-serious \\
\hline & & Fatigue & Non-related & Serious \\
\hline & & Oesophagitis & Suspected & Serious \\
\hline 37 & 2 & Urinary tract infection & Non-related & Non-serious \\
\hline \multirow[t]{6}{*}{45} & 2 & Abdominal Pain & Non-related & Non-serious \\
\hline & & Anaemia & Suspected & Serious \\
\hline & & Constipation & Non-related & Non-serious \\
\hline & & Leukopenia & Suspected & Serious \\
\hline & & Thrombocytopenia & Suspected & Serious \\
\hline & & Urinary tract infection & Suspected & Serious \\
\hline 85 & 2 & Metastases to central nervous system & Non-related & Non-serious \\
\hline $152^{\mathrm{b}}$ & 3 & Dyspnoea & Non-related & Non-serious \\
\hline \multirow[t]{4}{*}{210} & 2 & Dyspnoea & Non-related & Non-serious \\
\hline & & Fatigue & Non-related & Serious \\
\hline & & Oedema peripheral & Non-related & Non-serious \\
\hline & & General physical health deterioration & Non-related & Non-serious \\
\hline \multirow[t]{3}{*}{230} & 2 & Thrombocytopenia & Suspected & Serious \\
\hline & & Leukopenia & Suspected & Serious \\
\hline & & Nausea & Non-related & Non-serious \\
\hline 248 & 3 & Nausea & Non-related & Non-serious \\
\hline
\end{tabular}

${ }^{a}$ For $13 \mathrm{mCRC}$ patient (ECOG $\geq 2$ ) no. 21, 49, 68, 138, 188, 192, 219, 222, 226, 250, 251, 255 and 257 no data of adverse events are available

${ }^{\mathrm{b}} \mathrm{mCRC}$ patients $(\mathrm{ECOG} \geq 2$ ) with prior Regorafenib treatment

distribution, KRAS mutational status of patients as well as time from diagnosis of colorectal cancer was consistent between the German CUP and the phase 3 trial, though the mean body surface area in the CUP was slightly higher (1.87 vs. 1.781 , respectively) leading to a higher daily dose of FTD/TPI $(130 \mathrm{mg})$ compared with the RECOURSE trial (120 mg) (suppl. Table 1). However, in comparison with the RECOURSE trial, the patient population within the German CUP had two major differences indicating that phase 3 trials do not always reflect clinical experience in a real-life setting. First, in our study $9.8 \%$ of patients with an ECOG performance status of $\geq 2$ were included whereas patients with poor performance status were excluded in the RECOURSE trial (0\%). Thus, our cohort represents a more "real" patient population in daily clinical practice. We do not observe any remarkable difference in the safety profile of FTD/ TPI or in the duration of treatment in patients with an ECOG PS $\geq 2$. Among the 22 patients with ECOG PS $\geq 2$ only 3 discontinued treatment with FTD/TPI due to AEs. Thus FTD/TPI seems to be tolerated and effective even in patients with poorer performance status. We did not detect any unexpected safety signals with comparable characteristics and incidence of AEs and SAEs. However, the incidence of hematological AEs and other laboratory abnormalities was lower compared to the RECOURSE trial, presumably due to a underreporting of these AEs in CUPs. This is in line with the findings of a postmarketing surveillance study in 3.420 patients treated with FTD/TPI from May to November 2014 in Japan [17]. In this large observational study the safety profile was also similar to those from the RECOURSE trial. Furthermore, an expanded-access program (EAP) in the USA was carried out to further assess the safety profile of FTD/TPI in a real-world setting in 549 US patients with refractory mCRC. In this EAP, patients had a comparable exposure duration to that reported in 64 US patients who had participated in the RECOURSE trial, with no unexpected safety concerns [18]. In the EAP, only $4 \%$ of patients discontinued the treatment with FTD/TPI due to AEs [18]. Finally, a recent Spanish CUP conducted with refractory $538 \mathrm{mCRC}$ patients supported 
the findings of the German CUP presented here. In the Spanish CUP, FTD/TPI was generally well tolerated and the real-world data analysis was consistent with that reported in phase 3 trials of FTD/TPI in patients with mCRC [19]. In contrast to other European countries regorafenib is not longer available for patients in Germany since 2016. For this reason the number of patients in the German CUP, which were pretreated with regorafenib, is significantly lower than in patients of other European CUPs published recently. For example $70 \%$ of patients in the Italian CUP were pretreated with regorafenib compared to only $33.6 \%$ in the here reported patient population [20]. In addition, in Germany patients with advanced CRC are not only treated in large academic centers but also in smaller hospitals or private practices. For this reason 118 centers participated in the German CUP and enrolled 226 patients in total. So, there was a high variability in the experience of treating advanced CRC among the physicians. In contrast in other European countries like the Netherland the treatment of patients with advanced cancers is more centralized. In line, in the Netherlands' CUP 148 patients were enrolled in only 17 centers [21]. Taken together, the here reported patient population of the German CUP differs from those previously reported.

The data from this CUP is limited because long-term follow-up to analyze survival outcomes of the patients was not allowed due to regulatory affairs. Nevertheless, our study confirms findings of previous data that the safety profile of FTD/TPI was comparable to the pivotal trial RECOURSE and that the drug is well tolerated in a real life setting $[18,19,22]$. Moreover our data show that patients with an ECOG performance status of $\geq 2$ and/or previously treated with regorafenib can recieve FTD/TPI safely and effectively. Further clinical trials should investigate these patient groups with respect to efficacy as well as safety with a focus on the sequence of FTD/TPI and regorafenib.

\section{Conclusion}

In a prospective CUP in Germany conducted with pretreated mCRC patients the safety profile of FTD/ TPI was investigated in a real-world setting. FTP/ TPI was well tolerated in clinical practice. The patient characteristics and the toxicities of FTD/TPI documented in the German CUP were comparable with those reported in the pivotal RECOURSE trial without any unexpected safety signals. However, in the German CUP a higher number of patients had an ECOG performance status of $\geq 2(9.7 \%$ vs. $0 \%$ in RECOURSE) and the previous use of regorafenib was more common in the real-life setting (33.6\% vs.18\% in RECOURSE).

\section{Clinical practice points}

- The findings of this German CUP in line with other European, Asian and US American CUPs show that the safety profile of FTD/TPI in a real-world setting is comparable to that reported in the RECOURSE trial.

- FTD/TPI is generally well tolerated in clinical practice, even in patients with poorer performance status.

- In Germany, FTD/TPI is currently the only effective and safe anti-tumor agent available for patients with refractory $\mathrm{mCRC}$.

\section{Acknowledgements}

We thank all the patients and the participating centers for their contribution to the compassionate use program.

\section{Funding}

The compassionate-use program for Lonsurf ${ }^{\oplus}$ was supported by SERVIER Deutschland GmbH. SERVIER Deutschland GmbH designed the study, collected the data and funded the statistical analysis which was done by Anfomed $\mathrm{GmbH}$, Germany. The interpretation of the data and the writing of the manuscript were done by the investigators.

\section{Availability of data and materials}

The analysis of mCRC patient data along this Lonsurf ${ }^{\oplus}$ program was performed by Anfomed GmbH, Germany. The data and material for this manuscript will be made available from the corresponding author upon reasonable request and with permission of SERVIER Deutschland $\mathrm{GmbH}$.

\section{Authors' contributions}

SK interpreted the data and wrote the manuscript based on the raw data given by SERVIER Deutschland $\mathrm{GmbH}$. All other authors interpreted the data, read, corrected and approved the manuscript.

\section{Ethics approval and consent to participate}

According to the regulations of the German Medicinal Product Act (AMG $\$ 21$ subsection 2 no. 6), there was no need for an ethics approval in regard to the compassionate-use-program (CUP) for FTD/TPI (Lonsurf ${ }^{\oplus}$ ). Therefore, this program was not submitted to the ethics committee but reported to the German Federal Institute for Drugs and Medical Devices (BfArM). Patients were informed by the investigators about the CUP and had to sign an informed consent form (ICF) before beeing enclosed into the program. The ICF will be made available from the correponding author upon request.

\section{Consent for publication}

The informed consent form from Servier Deutschland GmbH contained a text passage "Confirmation of Use of Personal Medical Records and Personal Information" and each mCRC patient of the CUP for FTD/TPI (Lonsurf ${ }^{\circledR}$ ) agreed to the processing of pseudonymized personal data.

\section{Competing interests}

SK received authorship remuneration from SERVIER Deutschland GmbH (Germany). All other authors declare no competing interests.

\section{Publisher's Note}

Springer Nature remains neutral with regard to jurisdictional claims in published maps and institutional affiliations.

\section{Author details}

${ }^{1}$ West German Cancer Center, Department of Medical Oncology, University Hospital Essen, Essen, Hufelandstrasse 55, 45147 Essen, Germany.

${ }^{2}$ Community Praxis, Lübeck, Germany. ${ }^{3}$ Hospital Bogenhausen, Department of Gastroenterology, Hepatology and Gastrointestinal Oncology, Munich, Germany. ${ }^{4}$ Kliniken Essen-Mitte, Department of Medical Oncology, Essen, Germany. ${ }^{5}$ Hospital Altenburger Land, Department of Hematology and 
Oncology, Altenburg, Germany. ${ }^{6}$ Staedtisches Klinikum Neuperlach and Harlaching, Department for Hematology and Oncology, Munich, Germany. 7Department of Hematology and Oncology, Hospital Nordwest, Frankfurt/ Main, Germany. ${ }^{8}$ University Cancer Center Hamburg, University Medical Center Hamburg-Eppendorf, Hubertus Wald Tumor Center, Hamburg, Germany.

Received: 17 November 2017 Accepted: 7 November 2018

\section{Published online: 16 November 2018}

\section{References}

1. Robert Koch-Institut und Zentrum für Krebsregisterdaten. Bericht zum Krebsgeschehen in Deutschland 2016; 2016. Available at: https://www. krebsdaten.de/Krebs/DE/Content/Publikationen/Krebsgeschehen/ Krebsgeschehen_node.html. Accessed 25 July 2017.

2. Loupakis F, Cremolini C, Masi G, Lonardi S, Zagonel V, Salvatore L, Cortesi E, Tomasello G, Ronzoni M, Spadi R, Zaniboni A, Tonini G, Buonadonna A, Amoroso D, Chiara S, Carlomagno C, Boni C, Allegrini G, Boni L, Falcone A. Initial therapy with FOLFOXIRI and bevacizumab for metastatic colorectal cancer. N Engl J Med. 2014;371:1609-18.

3. Venook AP, Niedzwiecki D, Lenz H-J, Innocenti F, Mahoney MR, O'Neil BH, Shaw JE, Polite BN, Hochster HS, Atkins JN, Goldberg RM, Mayer RJ, Schilsky $\mathrm{RL}$, Bertagnolli MM, Blanke CD. Cancer and Leukemia Group B (Alliance), SWOG, and ECOG (2014) CALGB/SWOG 80405: Phase III trial of irinotecan/5FU/leucovorin (FOLFIRI) or oxaliplatin/5-FU/leucovorin (mFOLFOX6) with bevacizumab (BV) or cetuximab (CET) for patients (pts) with KRAS wild-type (wt) untreated metastatic adenocarcinoma of the colon or rectum (MCRC). J Clin Oncol. 2017;32(5 Suppl):Abstract LBA3.

4. Saltz LB, Clarke S, Díaz-Rubio E, Scheithauer W, Figer A, Wong R, Koski S, Lichinitser M, Yang TS, Rivera F, Couture F, Sirzén F, Cassidy J. Bevacizumab in combination with oxaliplatin-based chemotherapy as first-line therapy in metastatic colorectal cancer: a randomized phase III study. J Clin Oncol. 2008;26:2013-9.

5. Yamazaki K, Nagase M, Tamagawa H, Ueda S, Tamura T, Murata K, Eguchi Nakajima T, Baba E, Tsuda M, Moriwaki T, Esaki T, Tsuji Y, Muro K, Taira K, Denda T, Funai S, Shinozaki K, Yamashita H, Sugimoto N, Okuno T, Nishina T, Umeki M, Kurimoto T, Takayama T, Tsuji A, Yoshida M, Hosokawa A, Shibata Y, Suyama K, Okabe M, Suzuki K, Seki N, Kawakami K, Sato M, Fujikawa K, Hirashima T, Shimura T, Taku K, Otsuji T, Tamura F, Shinozaki E, Nakashima K, Hara H, Tsushima T, Ando M, Morita S, Boku N, Hyodo I. Randomized phase III study of bevacizumab plus FOLFIRI and bevacizumab plus mFOLFOX6 as first-line treatment for patients with metastatic colorectal cancer (WJOG4407G). Ann Oncol. 2016;27:1539-46.

6. Van Cutsem E, Köhne CH, Hitre E, Zaluski J, Chang Chien CR, Makhson A, D'Haens G, Pintér T, Lim R, Bodoky G, Roh JK, Folprecht G, Ruff P, Stroh C, Tejpar S, Schlichting M, Nippgen J, Rougier P. Cetuximab and chemotherapy as initial treatment for metastatic colorectal cancer. New Engl J Med. 2009;360: 1408-17.

7. Douillard JY, Siena S, Cassidy J, Tabernero J, Burkes R, Barugel M, Humblet Y, Bodoky G, Cunningham D, Jassem J, Rivera F, Kocákova I, Ruff P, BłasińskaMorawiec M, Šmakal M, Canon JL, Rother M, Oliner KS, Wolf M, Gansert J. Randomized, phase III trial of panitumumab with infusional fluorouracil, leucovorin, and oxaliplatin (FOLFOX4) versus FOLFOX4 alone as first-line treatment in patients with previously untreated metastatic colorectal cancer: the PRIME study. J Clin Oncol. 2010;28:4697-705.

8. von Weikersthal LF HV, Decker T, Kiani A, Vehling-Kaiser U, Al-Batran SE, Heintges T, Lerchenmüller C, Kahl C, Seipelt G, Kullmann F, Stauch M, Scheithauer W, Hielscher J, Scholz M, Müller S, Link H, Niederle N, Rost A, Höffkes HG, Moehler M, Lindig RU, Modest DP, Rossius L, Kirchner T, Jung A, Stintzing S. FOLFIRI plus cetuximab versus FOLFIRI plus bevacizumab as first-line treatment for patients with metastatic colorectal cancer (FIRE-3): a randomised, open-label, phase 3 trial. Lancet Oncol. 2014;15:1065-75.

9. Leitlinienprogramm Onkologie 2014. S3-Leitlinie Kolorektales Karzinom, Langversion 1.1. Available at: https://www.awmf.org/uploads/tx_szleitlinien/ 021-007OLI_S3_KRK_2017-12_1.pdf. Accessed 14 Nov 2018.

10. Deutsche Gesellschaft für Hämatologie und medizinische Onkologie e.V. 2016a. Kolonkarzinom - Leitlinie - Empfehlungen der Fachgesellschaft zur Diagnostik und Therapie hämatologischer und onkologischer Erkrankungen. Available at: https://www.onkopedia.com/de/onkopedia/guidelines/ kolonkarzinom/@@view/html/index.html. Accessed 25 July 2017.
11. Deutsche Gesellschaft für Hämatologie und medizinische Onkologie e.V. 2016b. Rektumkarzinom - Leitlinie - Empfehlungen der Fachgesellschaft zur Diagnostik und Therapie hämatologischer und onkologischer Erkrankungen. Available at: https://www.onkopedia.com/de/onkopedia/guidelines/ rektumkarzinom/@@view/html/index.html. Accessed 14 Nov 2018.

12. Van Cutsem E, Cervantes A, Adam R, Sobrero A, Van Krieken JH, Aderka D, Aranda Aguilar E, Bardelli A, Benson A, Bodoky G, Ciardiello F, D'Hoore A, Diaz-Rubio E, Douillard JY, Ducreux M, Falcone A, Grothey A, Gruenberger T, Haustermans K, Heinemann V, Hoff P, Köhne CH, Labianca R, Laurent-Puig P, Ma B, Maughan T, Muro K, Normanno N, Österlund P, Oyen WJ, Papamichael D, Pentheroudakis G, Pfeiffer P, Price TJ, Punt C, Ricke J, Roth A, Salazar R, Scheithauer W, Schmoll HJ, Tabernero J, Taïeb J, Tejpar S, Wasan H, Yoshino T, Zaanan A. Arnold D. ESMO consensus guidelines for the management of patients with metastatic colorectal cancer. Ann Oncol. 2016;27:1386-422.

13. Benson AB 3rd, Venook AP, Bekaii-Saab T, Chan E, Chen YJ, Cooper HS, Engstrom PF, Enzinger PC, Fenton MJ, Fuchs CS, Grem JL, Hunt S, Kamel A, Leong LA, Lin E, Messersmith W, Mulcahy MF, Murphy JD, Nurkin S, Rohren E, Ryan DP, Saltz L, Sharma S, Shibata D, Skibber JM, Sofocleous CT, Stoffel EM, Stotsky-Himelfarb E, Willett CG, Gregory KM, Freedman-Cass DA, National Comprehensive Cancer Network. Colon cancer, version 3.2014. J Natl Compr Canc Netw. 2014;12:1028-59.

14. Mayer R, Van Cutsem E, Falcone A, Yoshino T, Garcia-Carbonero R, Mizunuma N, Yamazaki K, Shimada Y, Tabernero J, Komatsu Y, Sobrero A, Boucher E, Peeters M, Tran B, Lenz HJ, Zaniboni A, Hochster H, Cleary JM, Prenen H, Benedetti F, Mizuguchi H, Makris L, Ito M, Ohtsu A, RECOURSE Study Group. Randomized trial of TAS-102 for refractory metastatic colorectal cancer. N Engl J Med. 2015;372:1909-19.

15. Temmink OH, Emura T, de Bruin M, et al. Therapeutic potential of the dualtargeted TAS-102 formulation in the treatment of gastrointestinal malignancies. Cancer Sci. 2007;98:779-89.

16. DuBois $D$, DuBois EF. A formula to estimate the approximate surface area if height and weight be known. Arch Int Med. 1916;17:863-71.

17. Yoshino T, Uetake H, Fujita N, Furuta T, Katori J, Hara N, Muro K. TAS-102 safety in metastatic colorectal cancer: results from the first postmarketing surveillance study. Clin Colorectal Cancer. 2016;15:e205-11.

18. Mayer RJ, Grothey A, Hochster HS, Cohen S, Vukovic VM, Makris L. An openlabel expanded-access study of Trifluridine / Tipiracil for metastatic colorectal Cancer. J Clin Oncol. 2017;35:3559.

19. Alfonso PG, Carbonero RG, Carrato A, Vieitez JM. Gravalos5 C, Pericay C, Benavides M, Delgado M, Arguilles G, Ruiz a. compassionate use program with FTD/TPI (TAS-102) in pretreated metastatic colorectal cancer patients: Spanish real world data. J Clin Oncol. 2017;35:e15019.

20. Sforza V, Martinelli E, Cardone C, Martini G, Napolitano S, Vitiello PP, Vitale P, Zanaletti N, Reginelli A, Bisceglie MD, Latiano TP, Bochicchio AM, Cecere F, Selvaggi F, Ciardiello F, Troiani T. Clinical outcome of patients with chemorefractory metastatic colorectal cancer treated with trifluridine/ tipiracil (TAS-102): a single Italian institution compassionate use programme. ESMO Open. 2017;2:e000229.

21. Kwakman JJM, Vink G, Vestjens JH, Beerepoot LV, de Groot JW, Jansen RL, Opdam FL, Boot H, Creemers GJ, van Rooijen JM, Los M, Vulink AJE, Schut H, van Meerten E, Baars A, Hamberg P, Kapiteijn E, Sommeijer DW, Punt CJA, Koopman M. Feasibility and effectiveness of trifluridine/tipiracil in metastatic colorectal cancer: real-life data from the Netherlands. Int J Clin Oncol. 2017; 23(3):482-9 [Epub ahead of print].

22. Kotani D, Shitara K, Kawazoe A, Fukuoka S, Kuboki Y, Bando H, Okamoto W, Kojima T, Doi T, Ohtsu A, Yoshino T. Safety and efficacy of FTD/TPI monotherapy in clinical practice for patients with metastatic colorectal Cancer: experience at a single institution. Clin Colorectal Cancer. 2016; 15:e109-15. 